Article

\title{
Transformative Leadership and Contextual Change
}

\author{
John Grin ${ }^{1, *}$, Jan Hassink ${ }^{2}$, Vanja Karadzic ${ }^{3}$ and Ellen H.M. Moors ${ }^{4}$ \\ 1 Amsterdam Institute for Social Science Research, University of Amsterdam, \\ 1018 WV Amsterdam, The Netherlands \\ 2 Business Unit Agrosystems Research, Wageningen University \& Research, \\ 6700 AA Wageningen, The Netherlands; jan.hassink@wur.nl \\ 3 Foundation for Science and Technology, 1249-074 Lisbon, Portugal; v.karadzic@fct.unl.pt \\ 4 Copernicus Institute of Sustainable Development, Utrecht University, \\ 3584 CB Utrecht, The Netherlands; e.h.m.moors@uu.nl \\ * Correspondence: j.grin@uva.nl; Tel.: +31-20-5252108
}

Received: 30 May 2018; Accepted: 20 June 2018; Published: 25 June 2018

\begin{abstract}
Transitions to deal with the grand challenges of contemporary societies require novel kinds of leadership, which can both stimulate novel organizational practices and changes in practices and structures in the organization's context. This article seeks to understand how (changes in) the external structural context may influence organizational-internal transformative leadership and vice versa, and what kind of work is implied in leadership to transform current business models. It uses notions from literature on relational leadership and transformative leadership as sensitizing concepts. It then explores the leadership work in two case studies, on fishing in Portugal and care farming in the Netherlands. We find a dialectic interplay of the interactions between leaders and others on the one hand, and contextual changes on the other. Using a system-building perspective from innovation system literature, that interaction is driven by the quest to establish legitimacy and market formation and acceptance, knowledge and other resources for innovations.
\end{abstract}

Keywords: leadership; transitions; relational leadership; transformative leadership; innovation systems; value co-creation

\section{Introduction}

Grand societal challenges, such as climate change, urbanization, food security, and ageing, are generally seen in organizational studies as parts of a turbulent context to which organizations must adapt [1-4]. This obviously reflects the traditional central concern regarding how organizations ensure their fit with their environment [5,6]. Interestingly, Van Dijk [7] has recently reflected on the state of the art of leadership theory from the more engaged viewpoint of how organizations may contribute to resolving these challenges. As she notes, this often deals with novel, collaborative modes of value creation-more accurately, value co-creation between an organization and its social or physical context-such as closing substance cycles between a farm and surrounding nature, or the use of excess heat from data centers for home heating in an adjacent welling area. Value co-creation presents so-called "wicked problems", for which more than one solution exist, stakes are high and multiple actors are involved from various domains. Thus, as Van Dijk puts it, while "technical problems require good management, wicked problems require good leadership" Van Dijk [7] (pp. 17-18, our translation). Stipulating that good leadership is leadership that tailors itself to the specific problem at hand and for its context, she points to Complex Leadership Theory (CLT) as a promising approach.

CLT is rooted in complex adaptive systems theory [8], in which innovations emerge from complex, non-linear interactions between agents who deal with problems, often originating from the system's environment. CLT understands organizations as a complex system, embedded in a 
dynamic environment [9]. Mendes et al. [1] have aptly synthesized the work of different authors by conceiving complex system leadership "as a shared emergent process where individuals and teams interact and learn from each other to produce novelty and adaptive capacity [10-12]. In complexity leadership theory, leadership functions are not considered to be restricted to one specific person (e.g., CEO) or group (e.g., top management team). Instead, complexity leadership theory emphasizes creating organizational conditions that enable effective, but largely unspecified, future adaptive states. This means that formal leaders per se are not in full control of organizational dynamics, and co-workers are empowered to collectively learn and implement new solutions." Mendes et al. [1] (p. 302).

Such leadership, by its nature, will indeed adapt to the problem at hand and its context. Also, the idea that leadership is not a quality of the leader, but of her relations with others, as adopted from relational leadership theory, is obviously of key importance to new, collaborative models of value creation. Finally, the idea of empowerment of workers for engaging in innovations is also crucial here, not only for implementing such innovations, as Mendes et al. [1] say, but also for outlining and developing them to deal with, and make more structured, wicked problems. Yet, from the viewpoint of our interest in leadership for new value creation, there is an important limit. In CLT, as in organization studies and business administration more generally, leadership focuses on shaping the organization, adapting it to its environment which—although portrayed as mainly dynamic-is not seen as an object of intervention by the leader (cf. the review in [13]). As evidenced by multiple examples (e.g., [14-16]), practices for new forms of value creation struggle with their context and require contextual change to be successful. Leadership cannot just take context for granted and adapt to it; it will also need to consider the context as an object of intervention.

This can be understood more deeply based on transition theory $[17,18]$, in which a basic proposition is that dominant societal problem definitions, social practices and (discursive, institutional and material) structures co-evolve over time. Thus, when problems have been on the agenda for a prolonged time, a regime will emerge: a coherent and self-reproducing system of practices to deal with these problems, and associate structures. This regime nurtures "regular" practices and privileges them over innovative ones which, due to a misfit with regime practices and structures, may be hampered by inertia and resistance. Two often-encountered expressions are that (i) attempted novel practices lose their more deviant features (e.g., because the actors involved consider feasibility based on incumbent assumptions and fit with existing rules) and (ii) where practices maintain some "deviance", they may fail precisely for not fitting the incumbent regime [19-21]. Transition theory therefore designates such problems as not merely wicked, but even persistent: the system from which the problem arises, complicates resolving them. The above observation on organizations seeking to establish new modes of value creation can be understood as a case in point.

Under such circumstances, leadership must not only adapt the organization's practices and structures to context, but also its (relations to) contextual practices and structures. In other words, leadership is about shaping the co-evolution of organization and context. In this article, we seek to explore, through two case studies, the work implied in such leadership. More specifically, we aim to better understand how (changes in) the external structural context may influence organizational-internal transformative leadership and vice versa, and what kind of work is implied in leadership to transform current business models.

Our focus on the interaction between (changes in) external context and organizational-internal changes reflects to a key insight from complex adaptive systems theory: that the governing system must be understood as, or is essentially bound to become, part of the system to be governed (Loorbach [22], p. 175). The work of complexity leadership has, however, hardly been conceptualized. We will start with theoretical notions on various leadership theories, i.e., relational and transformative leadership, and innovation systems theory from transition studies. This leads to our conceptual framework on relational and transformative leadership in context. In the methodology, we present the analytical design for our exploration. Then, we introduce the two illustrative case studies on a fishery organization in Portugal and on a care farming organization in the Netherlands respectively. 
We analyze the forms of leadership involved, and the co-evolution of these organizations in their context. We end by discussing potential theoretical contributions and concluding remarks.

\section{Theoretical Notions on Leadership in Context}

Complexity Leadership Theory has adopted a specific form of leadership, i.e., relational leadership, claiming that this facilitates the realization of innovations $[4,9,23]$. Central to relational leadership is the recognition that leadership in novel value creation models is in relations. Sharma et al. [24], writing on healthcare innovation, has also stipulated that leadership cannot be controlled by an individual: rather it must be interdependent leadership operating at all levels of an organization. This has been confirmed in a comparative analysis by Uruena et al. [25]. Transformative leadership helps to understand how leadership may empower players for innovation.

However, the work involved in leadership for promoting innovative practices remains hitherto under-investigated (but see e.g., [26]), and this is even more the case for the work involved in co-shaping innovations and context. There is thus no fully fledged analytical framework available. We will therefore, instead, propose a proper set of sensitizing concepts, drawing on three bodies of literature. Two focuses on the interaction between leaders and others: to identify some that fit the collaborative nature of innovations, relational leadership literature offers some help; to appreciate how to achieve the transformational character of the innovations, we will complement this with some notions from transformational leadership literature. To understand the dynamics of co-shaping innovations and context, we will use concepts from innovation systems theory.

\subsection{Characteristics of Relational and Transformative Leadership}

Relational leadership literature, emphasizing the distributed nature of leadership, suggests multiple elements of the work involved. Firstly, it emerges from a group of interacting individuals, featuring open boundaries, and the distribution of expertise across different participants, including communities and opinion leaders [27-29]. It is thus based on an organizational culture that allows taking decisions and communicating them transparently [30]. Secondly, relational leadership often leads to collaborative partnerships among leaders that aim to change the environment to improve population-level outcomes [31]. Thirdly, collaboration often aims at some sort of change or adoption of new behavior [32]. Fourthly, to gain advantage from relational or collaborative leadership, practitioners need to engage in continuous process of nurturing the collaborative/relational processes, often dealing with issues of trust [33] or legitimacy [34]. Uhl-Bien [23] sees relational leadership as a social influence process through which emergent coordination (e.g., evolving social order) and change (e.g., new approaches, values, attitudes, behaviors, ideologies) are constructed and produced.

Another area of leadership literature focuses on the (mutual, iterative) relation between a leader and her followers (e.g., [35,36]). This transformative leadership literature may help to understand the internal process associated with major innovations. Important are the involvement and motivation of, and relations between, the leader and followers. Culture, convictions, attitudes and values need to be transformed. Accordingly, Paffen [37] discerns four characteristics of transformative leadership: (1) inspiring motivation (the ability to persuade followers and to get along with a particular vision and ambition); (2) intellectual stimulation (to create awareness to view problems from different angles and encourage followers in finding of creative solutions); (3) individual involvement (creating context for knowledge-gathering); and (4) ideal influence (one is willing to engage with the case and open for personal sacrifice, enjoying trust and respect from the followers) [37]. Table 1 summarizes the characteristics of relational and transformative leadership (emphasizing the work involved) that will serve as sensitizing concepts. 
Table 1. Characteristics of Relational and Transformative leadership.

Characteristics of the Work of Relational Leadership
R1: ensuring an organizational culture that allows taking decisions and communicating them transparently
R2: establish collaborative partnerships among leaders that aim to change the environment
R3: promote collaboration aimed at some sort of change or adoption of new behavior
R4: make practitioners engage in continuous process of nurturing the collaboration, often dealing with issues
of trust or legitimacy
Characteristics of the Work of Transformative Leadership
T1: provide inspiring motivation (to persuade followers and to get along with a particular vision and ambition)
T2: provide intellectual stimulation (=to create awareness to view problems from different angles and
encourage followers in finding of creative solutions)
T3: stimulate individual involvement through creating context for knowledge-gathering and learning
T4: promote ideal influence (make others willing with the case and open for personal sacrifice, enjoying trust
and respect from the followers)

\subsection{Innovation System Theory}

Other bodies of literature yield insight into the dynamics of relations between leadership and external orders needed to realize innovations. Next to "leadership work" as explained in the former part, also "institutional work" needs to take place. Institutional entrepreneurship literature has explored how institutional change may be promoted by individuals or through collective action by actors/leaders undertaking a dialectical process of framing and legitimization [38], where institutions change through day-to-day activities of groups of individual actors [39]. Different actors will react differently when faced with innovation. The willingness of an actor to adopt an innovation is said to depend on whether the innovation is seen as a threat or an opportunity, e.g., competence-enhancing or -destroying [38]. Actors, facing an innovation, can try to create new institutions or change existing ones to better fit their needs. This is also called institutional work, a micro-perspective where institutions change through day-to-day activities of groups of individual actors [39]. The activities of leaders can influence the institutional context in a positive way, for example in the case of a leader starting research activities, or actor activities can have a negative impact, such as an actor lobbying against an innovation [40].

This process of changing a business or organizational environment is been usefully understood as system-building in literature on Technological Innovation Systems [41,42]. While institutional work is a major dimension of system-building, the latter also explicitly covers the establishment or transformation of material structures as well as discursive change via the motors of technical change such as resource mobilization and legitimacy creation. Such systems comprise interconnected actors, institutions, networks and artefacts that develop, produce, market, and regulate a particular innovation. System-building is "the deliberate creation or modification of broader institutional or organizational structures in a ... system carried out by innovative actors. It includes the creation or reconfiguration of value chains as well as the creation of a supportive environment" for an emerging innovation (Musiolik et al. [43], p. 1035, own translation). According to Planko et al. [44], this co-creation of a business ecosystem can be strategic and is thus formulated as strategic collective system-building. This concept describes "processes and activities that networks of actors can strategically engage in to collectively build a favorable environment for their innovative sustainability technology" ([44], p. 2328). Various types of system-building activities can be undertaken individually or collectively. Based on the categorization by Van de Ven [45] we focus on (i) knowledge and proprietary activities of organizations who carry out $R \& D$ in areas related to innovation; (ii) institutional arrangements including legitimation (i.e., creation of trust) and governance (i.e., norms, rules, regulations); and (iii) market formation. Much of the substance of the leadership work may thus be described as relational, transformative leadership (Table 1). What Innovation System literature adds is an understanding of the key activities of system-building (Hekkert et al. [42], the "motors" that drive the dialectic interplay of the interactions 
between leaders and others on the one hand, and contextual changes on the other: the quest to establish legitimacy and market formation and acceptance, knowledge and other resources for innovations. We will use these notions as foci for the secondary analysis of our two cases.

\section{Methodology: Analytical Design}

To discuss the work involved complexity leadership, we will use as "sensitizing concepts" [46] notions from three kinds of literature: relational leadership transformative leadership theory, and the Innovation System Building theory from transition studies to understand the dynamics of co-shaping an innovative practice and its context (see former section).

We use these sensitizing concepts to perform a secondary analysis of two earlier published cases. In line with our exploratory objective, we have selected them for variety in terms of context and the nature of the value creation proposition. The first case study $[47,48]$, on a fishery organization in Portugal, is at least initially on a very regular issue and remains located within one regime. It focuses on dealing with a typical common pool of resources (fish) problem, by eventually transforming the regime, removing the tension between producing a private good (fish) and maintaining a public value (biodiversity). It was based on interviews, documents and observations.

The second case study, care farming in the Netherlands [49] is initially located between two different regimes, that of agriculture and that of health care, but may be read as the start of establishing from there a new "care farming" regime. The value creation challenge is to co-create (i) economic viability of food production by farmers who simultaneously do more justice to public values (e.g., animal welfare) and goods (soil quality, biodiversity etc.) under adverse economic and policy circumstances; and (ii) better capacity to maintain another public value, health, in particular for so-called non-communicable diseases, which the incumbent health system (which is also under pressure due to sociological trends) finds hard to meet. This case study too was originally based on interviews, documents and observations.

We understand that the aforementioned two cases do not exhaust the conceivable set of cases. Other types of cases (including cases in which leadership is exercised by a team rather than a single person) need to be explored in the future. Also, more ambiguous cases, comprising episodes of more and less successful leadership, may yield further understanding. Yet, these two cases are different enough to enable a first exploration and gain some insights. For each of these cases, we will follow the development of innovative practices from a "dual vision" ([17], pp. 315-319): An action perspective-more particularly the perspective of the project leadership—analyzed through a "follow-the-actor" approach, based on a description of leadership intervention and the underlying motives and considerations, and a meta-perspective-analyzing the dynamic relationship between the project and its context, by focusing on both the "autonomous" changes in structural context and the influence of the agency of the leader. In transition studies, this helps analyze transformation through a structuration lens, i.e., recognizing that structure is both medium and outcome of (transformative or self-reproducing) practices [50]. In terms of organizational studies, it helps us to do justice to agency, in line with Baum and Shipilov's [51] pledge, to avoid structural determinism while recognizing the importance of context as a supplier of resources (organizational ecology literature, cf. [52,53] and as hampering change (structural inertia theory, cf. [54,55].

\section{Case Study: Fishery in Portugal}

Our first case, a secondary analysis of the study by Karadzic et al. [47], focuses on the ArtesanalPesca fish Producers Organization (PO) from Sesimbra, Portugal. POs are a construct under the EU's common market policies with the authority to regulate the market and plan fish landing and processing in a specific region. While membership is voluntary, members are obliged to sell their fish through their $\mathrm{PO}$, which in turn offers benefits such as marketing efforts and a minimum price, guaranteed by the EU. 
In Portugal, about one third of all vessels (accounting for $78 \%$ of all landings) has joined one of the fifteen POs. Fish is typically sold through "descending-bid" type auctions on, moreover, a rapidly fluctuating market. This enables downward price manipulation by retailers, especially in time of oversupply. The resultant income uncertainty then makes fishermen fish more, which on the one hand yields a threat to the fish stock, and on the other puts further downward pressure on the prices they receive. Thus, arises what we will further call a dual detriment. That detriment also is rooted in the fishermen's traditional, historical-institutional shaped market-averse attitude. Even before the EU system, the corporatist system under the Salazar regime had produced weak self-organizing capacity and as a result a rather limited self-understanding among fishermen as the ones who would just bring the fish to land, while others would sell it and pay the fishermen a fair price for it.

ArtesanalPesca (Sesimbra, Portugal) is the only PO entitled to catch black scabbard fish in Portuguese continental waters; typically, this is done through longline fishing. In addition, its members catch other species, such as mackerel, sardines and octopus. Depending on market demand, they leave the port two or three times a week. Founded in 1986, it went through a major conflict between 1993 and 1995, when its leadership decided to build a storage facility that could help dampen market fluctuations and thus the dual detriment. Only twenty vessel owners were prepared to contribute financially to the plan. The still young organization lacked experience with and practice in taking and communicating such decisions (R1, R4 lacking), and it was difficult for leadership to convince the other two thirds of the members to support the plan (R3 lacking). These members then left the organization.

By December 2004, however, many of them joined the "remainers" when heavy black scabbard fishing made the prices drop to the extent that interrupting fishing became the least disadvantageous option. Vessel-owners dedicated to black scabbard fish (most of them left the organization during 1993-95) requested a meeting with the ArtesanalPesca and it was the way that ArtesanalPesca's leadership responded to this crisis that transformed both the organization and its context. While supporting the fishermen's catch stop, they also sought to exploit the crisis to explore a more fundamental solution which, they realized, would require collaboration between as many vessel owners as possible (R3). They thus invited the "leavers" to re-join the PO, much to the chagrin of those who had remained and invested in the new facility. Through several meetings (T3), leadership settled the dispute. In doing so, it could draw on the crisis, which affected both members and former members, and made them open to looking at their context in different ways (T2) and re-consider their preparedness for further collaboration (R3). By January 2005, most vessel owners were members again.

This set the stage for ArtesanalPesca leadership to pursue, in the following months, two (material and institutional) structural changes. First, it had a freezing facility installed and started to process, package and store its products. Second, drawing on the power base it established annual contracts with retailers for providing agreed, significant amounts of fish at a fixed price, higher than the average auction price. Obviously, these internal (material) and external (institutional) changes potentially could reinforce and enabled each other. Together, they largely re-solved the "dual detriment" mechanism: fish stocks were maintained better, and social-economically the benefits were tremendous: no occasional excess supply so no need to get the minimum price anymore, but rather higher prices throughout and stable incomes. Yet, pursuing and investing in these changes was a daring kind of experimentation at the time, when the preparedness for collaboration that created (R3) was still fragile. It could be undertaken because leadership had created, as Karadzic et al. [47], (p. 36) put it, a supportive learning environment that made these processes possible: "learning by doing" to solve internal conflicts and resistance; learning and sharing from experiences to increase mutual trust and improve relationships; learning how to react. Leadership drew on this learning environment of the crisis to stimulate a change of perceptions of context and self (T2). It was not at all certain that these changes would last, and thus required some courage to nevertheless make the significant investments needed for the storage and processing facilities. That things nevertheless worked out successfully was due to some other pieces of work by leadership. Crucial was the principal manager's relational competence in credibly justifying and managing investments, and in networking and negotiating (R2, R3, R4). While his (especially 
external) success in doing so yielded him additional trust and credibility and thus both increased members' willingness to support his strategy (T4) it would soon appear how fragile this still was.

That moment occurred when the auction market, where less fish was offered, responded to the new situation by increasing prices. That made some members sell their fish directly at the auction, rather than to the PO as agreed. This damaged everyone: auction prices went down again, the PO had to buy, at higher costs, part of its fish at the auction to fulfill its contractual obligations with retail, and it undermined trust between the PO members. It was through a new series of meetings, creating opportunities for collective learning, drawing on (figures about) the experiences gained both at the auction and at the new own system (T3). Through the process, he increased his capacity to motivate and stimulate members (T1, T2) enough to stabilize their new perceptions of their role the market and the need to collaborate. By 2007, 100\% of the black scabbard fish was offered to the PO. Fishermen's perceptions had changed, they had come to trust and respect leadership and they had been empowered to assume an active role in changing the system: from "reacting" to systems problems to "acting" to change the structures and behaviors that designed the problems. Simultaneously, the external structural changes realized by leadership had improved the organization's adaptive capacity. New challenges and novel solutions kept emerging and demanded alertness and resilience. Therefore, the system was still in a state of (sometimes very) dynamic equilibrium. Yet, two things had changed: it was a different state of equilibrium, where some of the original tensions between the different values to be pursued (meeting market demand, maintaining fishermen's incomes and maintaining fish stocks proper levels) had been relieved. Second, the changes just discussed together improved the adaptiveness of the system.

\section{Case Study: Care Farming in the Netherlands}

Care farms provide health and social services through involving clients in agricultural production: a typical example of joint value creation, to which at least two regimes serve as contexts: health care and agriculture. For farmers, it yields additional income in times in which other economic activities than primary production has become essential for making sufficient money. For the health sector where the increasing importance of non-communicable diseases and changing political views on the welfare state have generated an interest in deinstitutionalization and socialization of care and more emphasis on the agency of clients. (Hassink [49], chapter 1)

In the care domain, the demographic and epidemiologic transitions (ageing and the shift in emphasis towards chronic diseases), concerns on the long-term affordability of the current care system and sociological trends (individualization and a longing for more autonomy) all press on incumbent care practices and their institutional and discursive embedment [56]. In agriculture, liberalization of global trade, the need to deal with climate change and increasing scarcity of key resources such as phosphates, societal concerns about animal welfare are among the developments that press on the EU Common Agricultural Policy and agrifood value chains [57]—with due consequences for farmer incomes. This has led to a quest for "multifunctional agriculture" [58,59], including care farming in which care clients receive care through participating in agricultural production.

Care farming is a rapidly expanding sector in Europe, and the Netherlands is a frontrunner [60]. In the rapid expansion of Dutch care farming, regional organizations of care farmers, set up to collectively promote business opportunities in the care sector, have played a key role. Referring to Hassink [49] for a more comprehensive account of these various factors and their action, we here rely on a secondary analysis of his comparative article on two regional organizations to explore the workings of leadership in system innovations (Hassink et al. [61]; where indicated, also using some data and findings from Hassink et al. [62]).

The two organizations, BEZIG (Wageningen, The Netherlands) and Landzijde (Purmerend, The Netherlands), differ in terms of the results they managed to realize. Put briefly, compared with BEZIG, Landzijde managed to increase resources obtained from the care sector at a considerably higher rate, and managed to generate resources not only from health insurers but also from other 
organizations, such as reintegration firms and the city of Amsterdam. These differences appear to be largely attributable to differences in the strategies developed by the leadership of the organizations.

Landzijde was established by a farmer as a foundation to embed care farming in the care sector, to seize the opportunity implied by, on the one hand, the vicinity of many care clients in several big cities and the support from province, and, on the other hand, the lack of competence and interest among most farmers to embed themselves in the care sector. His primary conviction was that the success of Landzijde would mainly depend on the degree to which it would establish legitimacy in, and (thus) gain resources from, the care sector; and that, therefore, client needs should be central to Landzijde's endeavors. This vision and ambition (T1) together with his thirst for knowledge of the care sector (T3) and the fact that he himself was satisfied with a relatively small salary (T4) generated legitimacy and trust during his intense engagement with one insurance company (R4) who then helped him open doors among other insurance companies, while the director himself worked hard to develop legitimacy and trust among care organizations (R2), following the principle to work only with care organizations with ambitions-i.e., fellow transformative leaders (T1). As described in Hassink et al. [62], his mobilization of insurers and provincial support provided him with the resources to hire professionals well acquainted with the rules and realities of the care sector (T3), and not in for "big money" (T4). They helped him to develop quality standards (T2), which in turn further increased legitimacy and trust among insurers, and to benefit from a provision in care legislation where clients could spend a certain budget on care providers of their own choosing, provided that it fulfilled proper quality standards. In these ways, Landzijde could generate resources in a way that allowed for rapid expansion. These quality standards and the expertise of Landzijde employees also formed the basis on which Landzijde could help care organizations to develop innovative care practices, which in turn helped generate trust between Landzijde and these organizations (R4) as well opportunities to draw on, and contribute to, innovation programs (T3, R4)

Simultaneously, Landzijde's director managed to build a network in the primary sector. He started with enrolling and engaging respected farmers (R2, R4) who found his vision and innovative ambition attractive (T1), which helped to raise confidence among a wider set of farmers [62]. This confidence was, of course, further increased by Landzijde's proven capacity to mobilize resources and attract clients. That legitimacy also created a culture in which farmers were more forced to attend quarterly network meetings and were prepared to let themselves be professionally educated (R4, T3) in adopting professional practices (R3, T1) of care farming, in accordance with quality standards. The Landzijde director deliberately combined working in such collaborative and supportive relationships with nurturing central, yet transparent decision making (R1) without active involvement of the farmers, but with active involvement of clients.

Importantly, while this way of working with "his" farmers allowed him to act as an active, creative institutional entrepreneur, it also worked the other way around: his success in connecting to and transforming context generated and reinforced Landzijde's legitimacy, which was the basis for accepting this organizational structure. In more general terms, a key condition for success was network building and collaborative engagement with farmers and network building and collaborative engagement with actors in the care sector.

\section{Discussion and Conclusions}

In this article, we have sought to analyze how organizational leadership may contribute to systemic innovations through reflexive agency, i.e., though not only changing internal practices and structures, but also through finding novel ways to relate to, or even co-shape, those in the organization's context. To answer this question, we have investigated two case studies in terms of how leaders drew on key features of relational and transformative leadership (Table 1). This has enabled us to contribute to a more fine-grained analysis of the actual work of transforming relations, showing how agency matters [51] and to further developing Complexity Leadership Theory, which considers 
the organization and its context basically as a whole, and therefore is particularly relevant for a new generation of creative, collaborative, network-based value creation.

Our case studies confirm the importance of the features emphasized in the literature on relational and transformative leadership. Based on innovation system literature, we may add to strategic leadership literature that the ways in which these features matter may be understood by stating that they are part of efforts of system-building, especially regarding legitimacy creation and market formation. In line with the findings of Planko et al. [44,63], we have found that joint vision and ambition [T1] are of key importance: they mobilize, both internally and externally, others [R2, T2] by indicating how a wicked problem may be fruitfully solved, and they provide orientation [R3] and legitimacy [R4] to the collective action implied in the systemic innovation. Collaborative/relational processes are important to generate trust or legitimacy [R4]. In line with findings by Grin [64], the need for trust and legitimacy appear to be crucial drivers of system-building and of leadership. While Technological Innovation Systems literature has drawn some attention for legitimization, especially in relation to knowledge generation and mobilization, our findings suggest that this element deserves more attention.

Furthermore, as another confirmation of the findings of Planko et al. [44,63], the role of experts, expertise and knowledge is of key importance, resonating with Thornton's institutional order of profession [65]. This may be well understood from a system-building perspective: as Hekkert et al. [42] argue, knowledge is essential to provide further guidance to the search process, and thus relating the innovation to knowledgeable actors and sources of knowledge (development) is of key importance. They also show how that process is intertwined with legitimization. We therefore argue that knowledge, and the contribution of knowledge acquisition and development to legitimization, deserves more attention in leadership literature. While in relational leadership literature there is hitherto virtually no attention to knowledge, our relational view on the intertwinement of legitimacy [R4] and knowledge generation and mobilization may be well incorporated in this approach. Work on transformational leadership, which mainly discusses knowledge in terms of generating a context for knowledge gathering through individual involvement, might offer a more comprehensive and fine-grained analysis by paying more attention to the collective and relational nature of knowledge. Our cases showed potential "motors" between knowledge gathering through intellectual stimulation, individual commitment combined with a lot of inspiration and idealism (i.e., transformational leadership), backed up by various relational leadership features, such as a transparent organizational culture, collaborative partnerships, and engagement and legitimacy of practitioners. Changes in shared beliefs within an organization, learning from outsiders, and repositioning or integration of resources, routines in the context of the farming and (health)care regimes respectively, are activities that iteratively influence and maybe reinforce each other, and could lead to transitions. These motors are also described by Hekkert et al. [42].

Our third main finding concerns mobilizing the financial resources needed for developing and realizing the innovation. This too may be understood from a system-building perspective: not only were collaboration and partnerships [R2, R3] part of establishing a new system in and of themselves, but they also were mainly driven by and helped to meet the quest for enabling the innovation by creating and/or relating to institutional funding provisions. This process is identified by Hekkert et al. [42] as another motor for system-building. It may be included in relational theory as both the driver and the potential result of partnerships and collaboration, and in transformational literature as a second incentive (next to intellectual stimulation, [T3]) to encourage the development of creative solutions and, maybe more importantly, to promote the further spread and upscaling of solutions realized by frontrunners.

Importantly, and as a further upshot of our analysis, these findings show that the leadership features identified in relational and transformational leadership literature (Table 1) are important for interactions both internal and external to the organization. Even stronger, these processes appear deeply intertwined, in ways that may be understood from a system-building perspective. Another way 
to put this is that we have shown how one may further develop Van Dijk's notion of complexity leadership through drawing upon key findings from earlier leadership literature and adopting a system-building perspective as proposed in Technological Innovation Systems literature. Such a synthesis may help to understand how leaders, in realizing new, network-based value propositions, are both shaped by and shaping a complex system that comprises actors and arrangements both internal and external to the organization. In fact, our analysis suggests that leadership does not take such boundaries as points of departure but works to achieve system-building both internally and externally in ways shaped by its quests for legitimacy, knowledge and funding. This both underlines and gives additional meaning to Van Dijk's [7] claim that such boundaries become increasingly blurred and decreasingly relevant.

Finally, this perspective yields additional insight in how leadership may change external context. It confirms earlier findings by authors such as Hargrave and Van de Ven [38] and Lawrence et al. [39]. Our use of insights from relational and transformational leadership theory adds to such work a more fine-grained understanding of the interactions between leadership and external context. We have already discussed one important new insight: the potential role of ideals and modesty. In addition, we have seen how system-building may involve a broader repertoire than this literature tends to discuss. Lawrence and Suddaby [66] describe three different types of institutional work: (1) creating; (2) maintaining and (3) disrupting institutions to make place for new ones. While we have clearly seen, and analyzed in a more fine-grained way, the first two types of work, we have not seen much of institutional disruption. What actually happened is that new institutional arrangements were created by (i) relating to and (ii) transforming diverse (e.g., care and agriculture) existing arrangements and power structures. This was not because incumbent arrangements did not imply inertia but because strategically operating system-building leaders saw pragmatic opportunities to create the arrangements they needed. Furthermore, it was important to develop an organization that would fulfil the expectations and requirements of the healthcare sector (especially regarding health insurers). Therefore the notion of ideal influence [T4] deserves more attention. In many cases, it was precisely the ability of leaders to suppress narrow self-interest and to display modesty in portraying their roles that supported creation of legitimacy and (thus) realized access to resources.

Further analysis is needed to see whether and under what conditions such action may still presupposes, for longer term success, institutional disruption-alternatively, productive interactions between novel practices and novel arrangements may make, paraphrasing Lenin's famous words, incumbent institutions wither away.

To that end, we may build upon some key features from the organizational ecology literature (e.g., Baum and Shipilov [51]) and structural inertia theory to further conceptualize the problem. Organizational ecology scholars argue that legitimacy is a key element for organizational survival $[52,53]$. A legitimate status is sine qua non for resources to be mobilized, and for demand to form and to acquire regulatory support. The notion of "density dependence" sees to the need for organizations that wish to pursue an innovation to achieve legitimacy by relating the innovation to as many external sources of legitimacy as possible. Organizational ecology assumes that a high density of the population is therefore likely to promote the development of a novel organizational practice. Against skeptics and critics who argue that this is an overly deterministic view, Baum and Shipilov [51] point out that "individuals matter", a point we take to mean here that leadership as agency (i.e., as "the capacity to act otherwise" Giddens [50]) matters. Structural inertia theory emphasizes that organizations often face difficulties in sufficiently swiftly changing their strategies and internal organization to changes in their context. They find that this is often the reason organizations are replaced by younger ones. There is a body of literature emphasizing that leadership is being shaped by historically grown "institutional logic", which have both material and symbolic elements. Thornton and Occasio $[67,68]$ elaborate how this logic shapes leadership and emphasize that they in turn have been historically shaped (and thus help to operationalize structural inertia). Thornton [65] produced six different institutional orders or sets of unique practices, symbols, and organizing principles that influence the behavior of an organization 
or individual. These include: the corporation, the state, the market, the family, the religion, and the professions. In more recent work, Thornton et al. [69] add the community as a seventh institutional order. Taking these institutional orders into account, leaders could for example have transformative capacity via their profession (e.g., legitimation of expert knowledge) or via the community they are acting in (e.g., professional bodies).

Taking these insights together, an organization derives its legitimacy from the ways it strategically ties up to its context; it will have to transform, to a greater or lesser extent, this embedment when it seeks to pursue an innovation in its practices. This paper showed the entanglement of internal and external leadership work to be performed. Using system-building literature, the identified innovation motors nicely showed the actual work to be done. What is still lacking, Baum and Shipilov ([51], pp. 100-101) argue, is a more fine-grained analysis of the actual work of transforming relations. More specifically, a system-building perspective adds at least two things to insights on institutional entrepreneurship. First, it enables us to appreciate the intertwinement of the work done on internal and on external practices and structures. Second, it helps us elaborate, in addition to work on the institutional dimension of structure, also work on discursive and material structures. A promising route for further research would be to investigate the institutional, material and discursive work implied in reflexive agency. Such studies may shed important new light on contemporary practices of value co-creation. In pursuing such studies it will, finally, also be interesting to include different forms of so-called "distributive leadership", located in teams or networks, rather than in individuals. Such leadership is encountered in many contemporary practices of value co-creation, such as citizen-led design of energy-neutral, circular economy urban neighborhoods.

Author Contributions: J.G. and E.H.M.M. conceived the paper, presented earlier versions at the International Conference on Innovation and Sustainability (IST Gothenburg 2017) and the WINIR 2017 Conference (World Interdisciplinary Network for Institutional Research) in Utrecht, and processed the feedback obtained, V.K. and J.H. did the original case studies' research and ensured they were properly represented in this paper.

Funding: This research was funded by the Dutch Science Foundation (NWO)'s Programme on Sustainable Models. The title of the project is: 'Managing the transition to sustainable business models: the role of leadership and measuring shared value creation', grant number (NWO 438-14-901).

Conflicts of Interest: The authors declare no conflict of interest.

\section{References}

1. Mendes, M.; Gomes, C.; Marques-Quinteiro, P.; Lind, P.; Curral, L. Promoting learning and innovation in organizations through complexity leadership theory. Team Perform. Manag. 2016, 22, 301-309. [CrossRef]

2. Schmitt, A.; Barker, V.L.; Raisch, S.; Whetten, D. Strategic renewal in times of environmental scarcity. Long Range Plan. 2016, 49, 361-376. [CrossRef]

3. Al Humaidan, S.; Sabatier, V. Strategic renewal in times of environmental scarcity: The mediating role of technology in business model evolution. J. Organ. Chang. Manag. 2017, 30, 106-120. [CrossRef]

4. Uhl-Bien, M.; Arena, M. Leadership for organizational adaptability: A theoretical synthesis and integrative framework. Leadersh. Q. 2018, 29, 89-104. [CrossRef]

5. Mintzberg, H. Structure in Fives: Designing Effective Organizations; Prentice Hall: Upper Saddle River, NJ, USA, 1983.

6. Morgan, G. Images of Organization; SAGE: London, UK, 2006.

7. Van Dijk, G. Organisatie Ecologie: Eenvoud in Complexiteit; Inaugural Lecture; Tilburg University: Tilburg, The Netherlands, 2014.

8. Holland, J.H. Hidden Order: How Adaptation Builds Complexity; Addison-Wesley: New York, NY, USA, 1996.

9. Uhl-Bien, M.; Marion, R.; McKelvey, B. Complexity leadership theory: Shifting leadership from the industrial age to the knowledge era. Leadersh. Q. 2007, 18, 298-318. [CrossRef]

10. Avolio, B.J.; Walumbwa, F.O.; Weber, T.J. Leadership: Current theories, research, and future directions. Annu. Rev. Psychol. 2009, 60, 421-449. [CrossRef] [PubMed]

11. Lichtenstein, B.B.; Plowman, D.A. The leadership of emergence: A complex systems leadership theory of emergence at successive organizational levels. Leadersh. Q. 2009, 20, 617-630. [CrossRef] 
12. Hazy, J.K.; Uhl-Bien, M. Changing the rules: The implications of complexity science for leadership research and practice. In The Oxford Handbook of Leadership and Organizations; Day, D., Ed.; Oxford University Press: Oxford, UK, 2014; pp. 709-731.

13. Oc, B. Contextual leadership: A systematic review of how contextual factors shape leadership and its outcomes. Leadersh. Q. 2018, 29, 218-235. [CrossRef]

14. Hoffman, J.; Loeber, A. Exploring the micro-politics in transitions from a practice perspective: The case of greenhouse innovation in the Netherlands. J. Environ. Policy Plan. 2016, 18, 692-711. [CrossRef]

15. Moss, T. Urban Sustainability Transitions; Frantzeskaki, N., Broto, V.C., Coenen, L., Eds.; Routledge: New York, NY, USA, 2017; Chapter 10; pp. 159-171.

16. Swilling, M.; Musango, J.; Robinson, B.; Peter, C. Flows, Infrastructures and the African Urban Transition. In Urban Sustainability Transitions; Frantzeskaki, N., Broto, V.C., Coenen, L., Eds.; Routledge: New York, NY, USA, 2017; pp. 311-330.

17. Grin, J.; Rotmans, J.; Schot, J. Transitions to Sustainable Development. New Directions in the Study of Long Term Structural Change; Routledge: New York, NY, USA.

18. Smith, A.; Voß, J.-P.; Grin, J. Innovation studies and sustainability transitions: the allure of adopting a broad perspective, and its challenges'. Res. Policy 2010, 39, 435-448. [CrossRef]

19. Roep, D.; van der Ploeg, J.D.; Wiskerke, J.S.C. Managing technical-institutional design processes: Some strategic lessons from environmental co-operatives in the Netherlands. Neth. J. Agrar. Stud. 2003, 51, 195-217. [CrossRef]

20. Grin, J. Health technology assessment between our health care system and our health. Exploring the potential of reflexive TA. Poiesis Prax. 2003, 2, 157-174. [CrossRef]

21. Bos, B.; Grin, J. “Doing” Reflexive Modernization in Pig Husbandry: The Hard Work of Changing the Course of a River. Sci. Technol. Hum. Values 2008, 33, 480-507. [CrossRef]

22. Loorbach, D. Transition Management: New Mode of Governance for Sustainable Development; International Books: Utrecht, The Netherlands, 2007.

23. Uhl-Bien, M. Relational Leadership Theory: Exploring the social processes of leadership and organizing. Leadersh. Q. 2006, 17, 654-676. [CrossRef]

24. Sharma, S.; Conduit, J.; Rao Hill, S. Organisational capabilities for customer participation in health care service innovation. Australas. Mark. J. 2014, 22, 179-188. [CrossRef]

25. Urueña, A.; Hidalgo, A.; Arenas, Á.E. Identifying capabilities in innovation projects: Evidences from eHealth. J. Bus. Res. 2016, 69, 4843-4848. [CrossRef]

26. Plowman, D.A.; Solanksy, S.; Beck, T.; Baker, L.; Kulkarni, M.; Travis, D. The role of leadership in emergent, self-organization. Leadersh. Q. 2007, 18, 341-356. [CrossRef]

27. Markle-Reid, M.; Dykeman, C.; Ploeg, J.; Kelly Stradiotto, C.; Andrews, A.; Bonomo, S.; Salker, N. Collaborative leadership and the implementation of community-based fall prevention initiatives: A multiple case study of public health practice within community groups. BMC Health Serv. Res. 2017, 17, 141. [CrossRef] [PubMed]

28. Lavizzo-Mourey, R. Halfway there? Health reform starts now. JAMA 2016, 315, 1335-1336. [CrossRef] [PubMed]

29. Locock, L.; Dopson, S.; Chambers, D.; Gabbay, J. Understanding the role of opinion leaders in improving clinical effectiveness. Soc. Sci. Med. 2001, 53, 745-757. [CrossRef]

30. Vanvactor, J.D. Collaborative leadership model in the management of health care. J. Bus. Res. 2012, 65, 555-561. [CrossRef]

31. Tsai Roussos, S.; Fawcett, S.B. A review of collaborative partnerships as a strategy for improving community health. Annu. Rev. Public Health 2000, 21, 369-402. [CrossRef] [PubMed]

32. Ansari, W.E.; Phillips, C.J.; Hammick, M. Collaboration and partnerships: Developing the evidence base. Health Soc. Care Community 2001, 9, 215-227. [CrossRef] [PubMed]

33. Vangen, S.; Huxham, C. Nurturing collaborative relations: Building trust in interorganizational collaboration. J. Appl. Behav. Sci. 2008, 39, 490-504. [CrossRef]

34. Suchman, M.C. Managing legitimacy: Strategic and institutional approaches. Acad. Manag. Rev. 1995, 20, 571-610. [CrossRef]

35. Fredericks, D.A. The Leader's Experience of Relational Leadership: A Hermeneutic Phenomenological Study of Leadership as Friendship. Ph.D. Thesis, Antioch University, Culver City, CA, USA, 2009. 
36. Cunliffe, A.L.; Eriksen, M. Relational leadership. Hum. Relat. 2011, 64, 1425-1449. [CrossRef]

37. Paffen, P. Wat is typerend voor transformationele leiders. Holl. Manag. Rev. 2011, 139, 8-14.

38. Hargrave, T.J.; Ven De, A.H. A collective action model of institutional innovation. Acad. Manag. Rev. 2006, 31, 864-888. [CrossRef]

39. Lawrence, T.; Suddaby, R.; Leca, B. Institutional Work: Refocusing Institutional Studies of Organization. J. Manag. Inq. 2010, 20, 52-58. [CrossRef]

40. Garrety, K.; McLoughlin, I.; Wilson, R.; Zelle, G.; Martin, M. National electronic health records and the digital disruption of moral orders. Soc. Sci. Med. 2014, 101, 70-77. [CrossRef] [PubMed]

41. Bergek, A.; Jacobsson, S.; Carlsson, B.; Lindmark, S.; Rickne, A. Analyzing the functional dynamics of technological innovation systems: A scheme of analysis. Res. Policy 2008, 37, 407-429. [CrossRef]

42. Hekkert, M.P.; Suurs, R.A.A.; Negro, S.O.; Kuhlmann, S.; Smits, R.E.H.M. Functions of innovation systems: A new approach for analysing technological change. Technol. Forecast. Soc. Chang. 2007, 74, 413-432. [CrossRef]

43. Musiolik, J.; Markard, J.; Hekkert, M. Networks and network resources in technological innovation systems: Towards a conceptual framework for system building. Technol. Forecast. Soc. Chang. 2012, 79, 1032-1048. [CrossRef]

44. Planko, J.; Cramer, J.M.; Chappin, M.M.H.; Hekkert, M.P. Strategic collective system building to commercialize sustainability innovations. J. Clean. Prod. 2016, 112, 2328-2341. [CrossRef]

45. Van de Ven, A.H. The Development of an Infrastructure for Entrepreneurship. J. Bus. Ventur. 1993, 8, $211-230$. [CrossRef]

46. Blumer, H. What is wrong with social theory? Am. Sociol. Rev. 1954, 19, 3-10. [CrossRef]

47. Karadzic, V.; Antunes, P.; Grin, J. How to learn to be adaptive? An analytical framework for organizational adaptivity and its application to a fish producers organization in Portugal. J. Clean. Prod. 2013, 45, $29-37$. [CrossRef]

48. Karadzic, V.; Antunes, P.; Grin, J. Adapting to environmental and market change: Insights from Fish Producer Organizations in Portugal. Ocean Coast. Manag. 2014, 102, 364-374. [CrossRef]

49. Hassink, J. Understanding Care Farming as a Rapidly Developing Sector in the Netherlands. Ph.D. Thesis, University of Amsterdam: Amsterdam, the Netherlands, 2017.

50. Giddens, A. The Constitution of Society. Outline of the Theory of Structuration; University of California Press: Berkely, LA, USA, 1984.

51. Baum, J.A.C.; Shipilov, A.V. Ecological Approaches to Organizations. In The Sage Handbook of Organizational Studies; SAGE: London, UK, 2006; pp. 55-110.

52. Markard, J.; Wirth, S.; Truffer, B. Institutional dynamics and technology legitimacy-A framework and a case study on biogas technology. Res. Policy 2016, 45, 330-344. [CrossRef]

53. Zimmerman, M.A.; Zeitz, G.J. Beyond survival: Achieving new venture growth by building legitimacy. Acad. Manag. Rev. 2002, 27, 414-431. [CrossRef]

54. Hannan, M.T.; Freeman, J. The Population Ecology of Organizations. Am. J. Sociol. 1977, 82, 929-964. [CrossRef]

55. Hannan, M.T.; Freeman, J. Structural Inertia and Organizational Change. Am. Sociol. Rev. 1984, 49, 149-164. [CrossRef]

56. Broerse, J.E.W.; Grin, J. (Eds.) Towards Systems Innovations in Health Systems; Routledge: New York, NY, USA, 2017.

57. Marsden, T.K. Food systems under pressure: Regulatory instabilites and the challenge of sustainable development. In Food Practices in Transition: Changing Food Consumption, Retail and Production in the Age of Reflexive Modernity; Spaargaren, G., Oosterveer, P., Loweber, A., Eds.; Routledge Studies in Sustainability Transitions; Routledge: New York, NY, USA, 2012; Volume 3, pp. 291-311.

58. Wilson, G.A. From productivism to post-productivism ... and back again? Exploring the (un)changed natural and mental landscapes of European agriculture. Trans. Inst. Br. Geogr. 2001, 26, 77-102. [CrossRef]

59. Wilson, G.A. Multifunctional Agriculture: A Transition Theory Perspective; CABI: Oxford, UK; Massachusset, CA, USA, 2007.

60. Di Iacovo, F.; O'Connor, D. Supporting Policies for Social Farming in Europe: Progressing Multifunctionality in Responsive Rural Areas; ARSIA: Florence, Italy, 2009. 
61. Hassink, J.; Grin, J.; Hulsink, W. Identity formation and strategy development in overlapping institutional fields: Different entry \& alignment strategies of regional organizations of care farms into the healthcare domain. J. Organ. Chang. Manag. 2016, 29, 973-993.

62. Hassink, J.; Grin, J.; Hulsink, W. Multifunctional agriculture meets health care: Applying the multi-level transition sciences perspective to care farming in the Netherlands. Sociol. Rural. 2012, 53, 223-245. [CrossRef]

63. Planko, J.; Cramer, J.; Hekkert, M.P.; Chapping, M.M.H. Combining the technological innovation systems framework with the entrepreneurs' perspective on innovation. Technol. Anal. Strateg. Manag. 2017, 29, 614-625. [CrossRef]

64. Grin, J. Verandering bewerken in een veranderende context: Lessen uit de transitie van de Nederlandse landbouw. Res Publica 2014, 56, 455-480.

65. Thornton, P.H. Markets from Culture: Institutional Logics and Organizational Decisions in Higher Education Publishing; Stanford University Press: Stanford, CA, USA, 2004.

66. Lawrence, T.B.; Suddaby, R. 1.6 Institutions and Institutional Work. In The SAGE Handbook of Organization Studies; SAGE: Thousand Oaks, CA, USA, 2006; pp. 215-254.

67. Thornton, P.H. William Ocasio Institutional Logics and the Historical Contingency of Power in Organizations: Executive Succession in the Higher Education Publishing Industry, 1958-1990. Am. J. Sociol. 1999, 105, 801-843. [CrossRef]

68. Thornton, P.H.; Ocasio, W. Institutional Logics. In The Sage Handbook of Organizational Institutionalism; Greenwood, R., Oliver, C., Sahlin, K., Suddaby, R., Eds.; SAGE Publications Inc.: Thousand Oaks, CA, USA, 2008; pp. 99-129.

69. Thornton, P.H.; Ocasio, W.; Lounsbury, M. The Institutional Logics Perspective: A New Approach to Culture, Structure, and Process; Oxford University Press: Oxford, UK, 2012.

(C) 2018 by the authors. Licensee MDPI, Basel, Switzerland. This article is an open access article distributed under the terms and conditions of the Creative Commons Attribution (CC BY) license (http:/ / creativecommons.org/licenses/by/4.0/). 